\title{
Depression, anxiety and associated factors among housemaids working in Addis Ababa Ethiopia
}

\author{
Alem K. Ejigu*, Zahra R. Seraj², Mahlet W. Gebrelibanos², Tolesa F. Jilcha and Yodit H. Bezabih²
}

\begin{abstract}
Background: Housemaids are part of women with low socioeconomic status and most of them are migrant from rural to central part of Ethiopia, less educated, either with poor, separated, single or divorced family and/or dead parents. Housemaid may experience problems like depression and anxiety more than other groups of women. Therefore, the aim of this study was to assess the magnitude and determinants of those problems among housemaids.
\end{abstract}

Objective: To assess the magnitude and determinants of depression \& anxiety among housemaids in Addis Ababa; Ethiopia; 2018.

Methods: Community based cross-sectional study was conducted from May 1 to August 30, 2018 among housemaids working in Addis Ababa, Ethiopia. Multistage sampling technique was applied with a total of 826 samples. Quantitative data was employed by using structured questionnaires. The collected data was coded, entered in to Epi-Info version 7 and analyzed by using SPSS version 20. Descriptive, analytical statistical procedures; bivariate and multivariate binary logistic regressions with odds ratios and 95\% confidence interval was employed.

The statistical significance was declared at $p$ value $<0.05$.

Results: This study enrolled 862 participants with response rate $99.5 \%, 99.5 \%$ refers to the number of people who actually completed the interview. The result showed prevalence of depression and anxiety among housemaids $27.5 \%$ and $32.3 \%$ respectively. Among all participants $44.6 \%(95 \% \mathrm{Cl}=41.0-47.9)$ have mild, $18.5 \%(95 \% \mathrm{Cl}=15.7-$ 21.2) have moderate and $6.1 \%(95 \% \mathrm{Cl}=4.5-7.8)$ have severe form of comorbid anxiety with depression. Depression (44.9\%) and anxiety (41.9\%) found more prevalent among the age group 16 to 20. In this study history of parental divorce, participant's divorce, physical violence and sexual violence are positively associated. Other factors; being less educated and living with relatives; were associated negatively.

Conclusion: The prevalence of Depression and Anxiety is found high among housemaid; its prevalence is more among age group 16 to 20 than other age groups. Violence, participant's divorce, history of parental divorce and contraceptive use has positively associated with depression and anxiety.

Keywords: Depression, Anxiety, Housemaid, Ethiopia

* Correspondence: alemkebede_2005@yahoo.com;

alemkebedeejigu@gmail.com

'Postcode 185093 Addis Ababa, Ethiopia

Full list of author information is available at the end of the article

(c) The Author(s). 2020 Open Access This article is licensed under a Creative Commons Attribution 4.0 International License, which permits use, sharing, adaptation, distribution and reproduction in any medium or format, as long as you give appropriate credit to the original author(s) and the source, provide a link to the Creative Commons licence, and indicate if changes were made. The images or other third party material in this article are included in the article's Creative Commons licence, unless indicated otherwise in a credit line to the material. If material is not included in the article's Creative Commons licence and your intended use is not permitted by statutory regulation or exceeds the permitted use, you will need to obtain permission directly from the copyright holder. To view a copy of this licence, visit http://creativecommons.org/licenses/by/4.0/ The Creative Commons Public Domain Dedication waiver (http://creativecommons.org/publicdomain/zero/1.0/) applies to the data made available in this article, unless otherwise stated in a credit line to the data. 


\section{Background}

\section{Statement of the problem}

Depression and Anxiety are common mental health problems among women worldwide [1-4]. In case of anxiety and depression; the greater vulnerability of women varies with the age: before mid-puberty, boys are more likely than girls to anxious or depressed, while between 15 and 19 years, the prevalence of depression is doubled in girls $[2,5]$. This trend persists until 54 years [3]. Depression is part of mental illness which is more prevalent among women and women in socioeconomic problems are more risky when compare with women in better socioeconomic status [6].

Housemaids are a relatively homogenous immigrant subgroup in terms of their gender, socio-cultural, educational and occupational background. Psychiatric morbidity among housemaids is two to five times higher than the native female population [7-9].

Housemaid the most common occupation in the female labor force which can generate mental suffering such as depressive and anxiety symptoms [10].

Poverty and hunger force many women to migrate as a survival strategy. In many countries, women migrants working in domestic service or factories are at high risk of experiencing abuse by employers including confinement, slave-like conditions, and physical and sexual assault in turn that may lead them to develop depressive or anxiety symptoms [7, 11].

Housemaids are part of community who leave their primary living place or their families because of challenging life events that obligate them to search other alternatives to survive or for perceived better life. The majority of housemaids are women, poor and immigrants with minimal education $[7,9,12]$.

In our country context responsibilities of housemaids vary and generally include cleaning \& arranging the house, compartment \& households; giving care for children \& entire families; cooking \& serving food for family members; in some context shopping \& managing the house at all. The specific tasks vary in each household's standard, family size and each employer's perception. Performing all those activities may lead them to stress and stress related problems [1, 13, 14].

Although there are many researches done; in the world including Ethiopia; on depression and anxiety among women, there is a serious lack of information on the magnitude, as well as factors associated with depression and anxiety among housemaid. This study was therefore aim at evaluating the magnitude and determinants of depression and anxiety among housemaids in Addis Ababa, Ethiopia.

\section{Objectives}

General objective:

To assess magnitude and determinants of depression and anxiety among housemaids in Addis Ababa, Ethiopia; 2018

\section{Specific objectives:}

To assess magnitude of depression among housemaids in Addis Ababa, Ethiopia; 2018

To assess magnitude of anxiety among housemaids in Addis Ababa, Ethiopia; 2018

To assess determinants of depression among housemaids in Addis Ababa, Ethiopia; 2018

To assess determinants of anxiety among housemaids in Addis Ababa, Ethiopia; 2018

\section{Methods}

\section{Study Design and Period}

Community based Cross-sectional study was conducted from May 1 to August 30, 2018 in Addis Ababa.

\section{Study Setting}

Addis Ababa is Ethiopian capital city which contained different groups of population in different socioeconomic status. The city has a group of population from entire parts of the country. Among them woman are part of population migrate to capital city due to different reasons like occupation, relationship, education and other socioeconomic problems. Occupational migrants include woman who engage in different labor works to survive and to get perceived better life. Shelter is among major security and safety problem for those migrant women. They struggle to solve such housing problems in different approaches like forming large group and sharing poor setting house, renting daily paid settings for night, living on the street, possibly depend on relatives and in most cases of women in labor worker; they employee as housemaid to solve those major housing problems. Housemaids are among member of community in Addis Ababa population. Majority of them are migrants form entire (East, West, South and Northern) parts of the country for perceived better life with limited knowledge about urbanization, low socioeconomic status and with major communication barriers. Situations in the capital town like infrastructures, culture, values and norms are stranger to them. Also they start working in the city without safety, security, training and orientation about the new environment, job and life style.

\section{Source and Study Population Source Population}

All housemaids working in Addis Ababa, Ethiopia 


\section{Study Population}

Our study population was all housemaids working in Addis Ababa who were available at the time of data collection in selected households.

\section{Eligibility Criteria}

Housemaids who have work experience more than six consecutive months back from data collection date were included in this study.

Non residential workers (not living together with employer) and housemaids who were previously diagnosed mental illness were excluded in this study.

\section{Sample Size and Sampling Procedures Sample Size Determination}

The minimum number of sample required for this study was estimated by using Single population proportion formula considering the following assumptions

$$
n=\frac{\left(\frac{Z \alpha}{2}\right)^{2} p(1-P)}{d^{2}}
$$

Where

$\mathrm{n}=$ minimum sample size required for the study

$\mathrm{Z}=$ standard normal distribution $(\mathrm{Z}=1.96)$ with confidence interval of $95 \%$ and $\alpha=0.05$

$\mathrm{d}=$ margin of sample error tolerated, $(\mathrm{d})=5 \%=0.05$

$\mathrm{P}=$ Proportion the sample size was determine for each of response variables and the maximum sample size was take

Considering non response rate of $15 \%$, the total sample size for the study was 826

\section{Sampling Techniques}

A multistage sampling technique was used and 3 sub cities selected from 10 sub cities. Then 3 Woredas selected from each sub cities by using simple random sampling method. The sample size was distributed to each selected Woredas proportionally to its household size. Computer generated lottery method was use to select household from each woreda, if there is no housemaid in selected household next or previous household was checked. In case of more than one housemaid at a household one selected randomly.

\section{Instruments used for data collection and data collection procedures \\ Instruments Used for Data Collection}

In this study, to assess Socio-demographic information, clinical data, depression, anxiety, factors associated with depression and to assess factors associated with anxiety we were using interviewer administered questionnaire. The questionnaire has five parts: $1^{\text {st }}$ part contains Sociodemographic data, $2^{\text {nd }}$ part contains depression and anxiety assessment tool, $3^{\text {rd }}$ part includes questions to assess violence (Physical, Emotional and sexual violence), $4^{\text {th }}$ part to assess presence of stressful life events and the last part contain semi structured questions to assess clinical data of participants.

Depression and anxiety were measured by using PHQ -4. It is four items assessment tools which have separate parts for depression and for anxiety. Two items for depression (the PHQ-2 has a sensitivity of $83 \%$ \& specificity of 90\%) and two items for anxiety (GAD-2 has sensitivity $88 \%$ \& specificity $81 \%-83 \%)$. Also PHQ -4 has potency to measure occurrence of both cases at a person. All the 4 items should answered on a four point (Likert type) scale from "not at all" through "several days" and "more than half the days" to "nearly every day" [15]. To assess violence, WHO violence assessment tool was used. It has three parts: sexual violence which has six questions, emotional violence and physical violence which has three questions for each. Presence of one 'Yes' in each category is enough to say possible domestic violence [16]. Daily Stress Full Life Events Measurement Scale (DSLEMS) to assess presence of Stressful Life Events and to obtain socio-demographic and clinical data a detailed self-designed semi structured questionnaire was administered to consented study participants.

\section{Data collection Procedure}

Quantitative data was employed to collect information. Amharic Version of structured and semi structured interviewer administered questionnaire was used to collect necessary data from study participants. The data was collected by 9 female health extension workers for 18 weekends.

\section{Data Quality Management}

To assure the quality of the data high emphasis was give in designing data collection instruments for its simplicity. Prior to data collection training was give for data collectors. The questioner was pretested before the actual data collection activities and necessary modification was done. The collected data was reviewed and checked for its completeness and consistency.

\section{Definition of Variables}

In this study depression and anxiety are dependent variables and socio demographic factors (age, educational level, marital status, salary, service year and family status), clinical factors (medical illness, family history of mental illness, Medications) and psychological factors (substance use, stress, violence) are independent variables.

Anxiety: it is explained by score on PHQ 4: a cut of point 3 and more on the 0 -to- 6 -point GAD-2 scale determine as anxiety [15]. 
Depression: score on PHQ 4: a cut of point 3 and more on the 0 -to-6 point PHQ-2 score determine as depression [15].

Depression with Anxiety: PHQ-4 scores were operationally categorized as mild, moderate and severe forms of comorbid depression with anxiety. 'mild' for PHQ -4 scores 3 to 5, 'moderate' for PHQ -4 scores 6 to 8 and 'severe' for PHQ -4 scores 9 to 12 [15].

House head: in this study it includes all independent house heads inside each formally numbered household

Housemaids: Females who are working in household either non residential (not living with employer) or residential (living with employer) system.

\section{Data Analysis}

Data was coded and entered into Epi-Info version 7 for cleaning, storing and recording. Then the data imported to computer software Statistical Package for Social Sciences version 20 (SPSS-20). Descriptive statistical procedures were utilized to estimate the prevalence of depression and anxiety among housemaids. Bivariate and multivariable logistic regression analyses were conducted to identify associated factors for depression and anxiety among housemaids. The strength of the associated factors was presented by odds ratio with 95\% CI. The independent variables that fulfill p-value less than 0.2 were tolerated and exported to multivariable logistic regression. P-values less than 0.05 were considered as statistically significance.

\section{Dissemination and Utilization of results}

The result of this cross sectional study will consider disseminating and allowed to utilize the following organizations.

$>$ To Amanuel Mental Specialized Hospital

$>$ To Federal minster of health

$>$ To Addis Ababa health bureau

$>$ Ethiopia Ministry of Women, Children and Youth

Affairs

$>$ To publish the research in scientific journals and to present it in different scientific conference.

\section{Results}

\section{Description of Socio Demographic Characteristics of} Respondents

This study enrolled 862 participants with response rate $99.5 \%, 99.5 \%$ is the number of people who actually completed the interview. Average age of housemaids was 20 \pm 4.53 ; range 15 to 46 years. Most (47.1\%) of the study participants were in the age group 16 to $20,27.5 \%$ of participants has work experience of 2 to 3 years. Majority (63.3\%) of participants were at primary level of Education, $60.9 \%$ were orthodox in religion. Majority (56.9\%) of respondent's salary is in range 501 to 1000.
Around $70 \%$ of participants were single in relationship, $37.2 \%$ visit their families more than a yearly bases, $25.7 \%$ of participants lost one of their parents, $65.9 \%$ of participants families not found nearly (Table 1).

\section{Description of psychological factors among housemaids}

Among 862 participants, if problem happened 51.7\% have difficulties to get family support. Prevalence of lifetime physical and sexual violence was $22.8 \& 12.5 \%$ respectively. Also $6.2 \%$ of participants had sexual violence at the age under 15 . Majority (73\%) of participants has domestic violence. Emotional violence was the most (64.30) prevalent type of violence when compared with physical and sexual violence (Table 2).

\section{Description of clinical factors among housemaids}

Among all participants 6.2\% have known medical illness and among them 41.18 take medication for medical illness. Also $14.5 \%$ of participants use contraceptive (Table 3).

\section{Prevalence of depression and anxiety among housemaid Prevalence of Depression among housemaid}

In this study prevalence of depression found 27.5\% (95\% $\mathrm{CI}=24.3-30.40)$. It is more $(44.9 \%)$ prevalent among the age group 16 to 20 year.

\section{Prevalence of Anxiety among housemaid}

Anxiety found more prevalent than depression it counts $32.3 \%$ (95\% CI $=29.3$ - 35.4). It accounts equal amount among the age groups 16 to $20(13.6 \%)$ and age group above 25 years $(13.6 \%)$.

\section{Prevalence of Comorbid Depression with Anxiety among Housemaid}

Among all participants $44.6 \%(95 \% \mathrm{CI}=41.0-47.9)$ have mild, $18.5 \%(95 \% \mathrm{CI}=15.7-21.2)$ have moderate and $6.1 \%(95 \% \mathrm{CI}=4.5-7.8)$ have severe form of comorbid Depression with Anxiety.

\section{Factors Associate with Anxiety and Depression among Housemaids \\ Factors associated with Depression}

The binary logistic (crude analysis) was done on sociodemographic (Age, marital status, educational status, service year, salary, family visit, Family support and parent's relationship status), clinical (contraceptive use); psychosocial factors (alcohol use, khat use, stress full life events, life time physical and sexual violence, under 15 sexual violence and domestic violence, ) were found to be p-value of less than 0.2 in Univariate logistic regression and taken in to multivariable logistic regression. The variable group expected to be protective against depression is treated as the reference group (Table 4). 
Table 1 Socio-demographic characteristics of housemaids: Addis Ababa, Ethiopia - 2018

\begin{tabular}{|c|c|}
\hline \multirow[t]{2}{*}{ Variables } & Results: $\boldsymbol{n}=826$ \\
\hline & Frequency (\%) \\
\hline \multicolumn{2}{|l|}{ Age } \\
\hline 15 & $29(3.50)$ \\
\hline $16-20$ & $389(47.10)$ \\
\hline $21-25$ & $85(10.30)$ \\
\hline$>25$ & $323(39.10)$ \\
\hline \multicolumn{2}{|l|}{ Service Years } \\
\hline 6 months & $143(17.30)$ \\
\hline 1 to 2 years & $191(23.10)$ \\
\hline 2 to 3 years & $228(27.60)$ \\
\hline 3 to 5 years & $69(8.40)$ \\
\hline$>5$ years & $195(23.60)$ \\
\hline \multicolumn{2}{|l|}{ Educational status } \\
\hline No formal education & $127(15.40)$ \\
\hline Primary education & $523(63.30)$ \\
\hline Secondary education & $163(19.70)$ \\
\hline Higher education & $13(1.60)$ \\
\hline \multicolumn{2}{|l|}{ Religion: } \\
\hline Orthodox & $503(60.90)$ \\
\hline Muslim & $112(13.60)$ \\
\hline Protestant & $209(25.30)$ \\
\hline Catholic & $2(0.20)$ \\
\hline \multicolumn{2}{|l|}{ Salary: } \\
\hline$<500$ & $36(4.40)$ \\
\hline $501-1000$ & $470(56.90)$ \\
\hline $1001-1500$ & $174(21.10)$ \\
\hline $1501-1200$ & $98(11.90)$ \\
\hline$>2000$ & $48(5.80)$ \\
\hline \multicolumn{2}{|l|}{ Marital Status: } \\
\hline Single & $660(79.90)$ \\
\hline Separated & $86(10.40)$ \\
\hline Divorced & $66(8.00)$ \\
\hline Widowed & $6(0.70)$ \\
\hline Married & $8(1)$ \\
\hline \multicolumn{2}{|l|}{ Family Visit: } \\
\hline$<$ monthly & $125(15.10)$ \\
\hline Monthly & $174(21.10)$ \\
\hline More than monthly & $185(22.40)$ \\
\hline Yearly or more & $307(37.20)$ \\
\hline Living with employer & $34(4.10)$ \\
\hline Missed & 1 \\
\hline
\end{tabular}

Table 2 Psychosocial characteristics of housemaids: Addis Ababa, Ethiopia - 2018

\begin{tabular}{lll}
\hline Variables & \multicolumn{2}{l}{ Results: $\boldsymbol{n}=826$} \\
\cline { 2 - 3 } & Yes & No \\
\hline Life time physical violence & $188(22.8)$ & $398(77.20)$ \\
Hard to get family support & $427(51.70)$ & $723(87.50)$ \\
Life time sexual violence & $103(12.50)$ & $775(93.80)$ \\
Under 15 Sexual Violence & $51(6.20)$ & $609(73.70)$ \\
Daily Stressful Life Events & $217(26.30)$ & $223(27.00$ \\
Domestic violence: & $603(73.00)$ & $295(35.70)$ \\
Emotional & $531(64.30)$ & $448(54.20)$ \\
Physical & $378(45.80)$ & $657(79.50)$ \\
$\quad$ Sexual & $169(20.50)$ & $812(98.30)$ \\
Substance use & & $794(96.10)$ \\
$\quad$ Khat & $14(1.70)$ & $818(99.00)$ \\
$\quad$ Alcohol & $32(3.90)$ & \\
Cigarette & $8(1.00)$ &
\end{tabular}

The odds of developing depression is increased 2.62; $(\mathrm{AOR}=2.62,95 \% \mathrm{CI}=1.46-4.71)$; times among divorced participants when compared with the single one.

The odds of developing depression is decreased by 48\%; (AOR=0.52, 95\% CI=0.29- 0.95); among participants who visit families in the period monthly to yearly when compared with those visit parents less than monthly.

The odds of developing depression is 2.10; $(\mathrm{AOR}=2.1$, $95 \% \mathrm{CI}=1.08-4.10$ ); times increased among participants whose parents are divorced and it increased 1.98; $(\mathrm{AOR}=1.98,95 \% \mathrm{ci}=1.31$ to 2.99$)$ times among participants who lost one of their parents when compared with participants whose parents are living together.

The odds of developing depression is 1.63; $(\mathrm{AOR}=1.63$, $95 \% \mathrm{CI}=1.13-2.37$ ); times increased among housemaid who had physical violence.

The risk of developing depression is 1.59; $(\mathrm{AOR}=1.59$, $95 \% \mathrm{CI}=1.01-2.52$ ); times higher among participants who had sexual violence.

The odds of developing depression is 2.19; $(\mathrm{AOR}=2.19$, $95 \% \mathrm{CI}=1.31$ - 3.67); times increased among housemaids who are using contraceptive than who are not using contraceptive.

Table 3 Clinical characteristics of housemaids: Addis Ababa, Ethiopia - 2018

\begin{tabular}{lll}
\hline Variables & \multicolumn{2}{l}{ Results: $n=826$} \\
\cline { 2 - 3 } & Yes & No \\
\hline Previously known medical cases & $51(6.20)$ & $775(93.80)$ \\
Medication for known case: $(n=51)$ & $21(41.18)$ & $30(58.82)$ \\
Contraceptive use & $120(14.50)$ & $706(85.50)$ \\
\hline
\end{tabular}


Table 4 Factors which has association with depression on binary logistic regression: Addis Ababa, Ethiopia- 2018

\begin{tabular}{|c|c|c|c|c|}
\hline \multirow[t]{3}{*}{ Variables } & \multicolumn{4}{|c|}{ Results: $\boldsymbol{n}=826$} \\
\hline & \multicolumn{2}{|l|}{ Depression } & \multirow[t]{2}{*}{ COR (Cl 95\%) } & \multirow[t]{2}{*}{ AOR (Cl 95\%) } \\
\hline & Yes & No & & \\
\hline \multicolumn{5}{|l|}{ Educational Status } \\
\hline No Formal Education & $44(19.40)$ & $83(13.90)$ & $.618(.196-1.953)$ & $0.28(0.08-0.98)^{*}$ \\
\hline Primary Level & $134(59.00)$ & $309(64.90)$ & $.402(.133-1.217)^{*}$ & $0.24(0.07-0.82)^{*}$ \\
\hline Secondary Level Education & $43(18.90)$ & $120(20.00)$ & $.418(.1333-1.313)^{*}$ & $0.25(0.07-0.87)^{*}$ \\
\hline College Level Education & $6(2.60)$ & $7(1.20)$ & 1.00 & 1.00 \\
\hline \multicolumn{5}{|l|}{ Relationship status } \\
\hline Single & $163(71.80)$ & $497(83.00)$ & 1.00 & 1.00 \\
\hline Separated & $25(11.00)$ & $61(10.20)$ & $1.25(0.76-2.06)$ & $1.27(0.75-2.19)$ \\
\hline Divorced & $33(14.50)$ & $33(5.50)$ & $3.05(1.82-5.10)^{* * *}$ & $2.62(1.46-4.71)^{* *}$ \\
\hline Widowed & $4(1.80)$ & $2(0.30)$ & $6.10(1.102-33.60)^{*}$ & $1.54(0.25-9.64)$ \\
\hline Married & $2(0.90)$ & $6(1.00)$ & $1.02(0.203-5.09)$ & $1.15(0.22-6.08)$ \\
\hline \multicolumn{5}{|l|}{ Vacation } \\
\hline Less than monthly & $32(14.10)$ & $93(15.50)$ & 1.00 & 1.00 \\
\hline Monthly & $51(22.50)$ & $123(20.50)$ & $1.23(0.72-2.02)$ & $0.83(0.46-1.47)$ \\
\hline Monthly to yearly & $36(15.90)$ & $149(24.90)$ & $0.70(0.41-1.21)$ & $0.52(0.29-0.95)^{*}$ \\
\hline More than Yearly & $92(40.50)$ & $215(35.90)$ & $1.244(0.78-1.99)$ & $0.83(0.49-1.40)$ \\
\hline Living with employer & $16(7.00)$ & $19(3.20)$ & $2.45(1.13-5.32)^{*}$ & $1.86(0.79-4.38)$ \\
\hline \multicolumn{5}{|l|}{ Parent R. condition } \\
\hline Living together & $87(38.30)$ & $321(53.60)$ & 1.00 & 1.00 \\
\hline Separated & $22(9.70)$ & $60(10.00)$ & $1.35(0.77-2.33)$ & $1.38(0.76-2.52)$ \\
\hline Divorced & $21(9.30)$ & $32(5.30)$ & $2.42(1.33-4.41)^{* *}$ & $2.10(1.08-4.10)^{*}$ \\
\hline Mother/ father lost & 77 (33.90) & $135(22.50)$ & $2.10(1.46-3.04)^{* * *}$ & $1.98(1.31-2.99)^{* *}$ \\
\hline Both parents lost & $20(8.80)$ & $51(8.50)$ & $1.45(0.82-2.55)$ & $1.22(0.64-2.34)$ \\
\hline \multicolumn{5}{|l|}{ Daily Stressful Life E } \\
\hline Yes & $76(33.50)$ & $141(23.50)$ & $1.99(1.45-2.72)^{* * *}$ & $1.31(0.89-1.91)$ \\
\hline No & $151(66.50)$ & $458(76.50)$ & 1.00 & \\
\hline \multicolumn{5}{|l|}{ <15 Sexual V. } \\
\hline Yes & $24(10.60)$ & $27(4.50)$ & $2.50(1.41-4.44)^{* *}$ & $1.81(0.84-3.88)$ \\
\hline No & $203(89.40)$ & $572(95.50)$ & 1.00 & 1.00 \\
\hline \multicolumn{5}{|l|}{ Physical violence } \\
\hline Yes & $131(57.70)$ & $247(41.20)$ & $1.94(1.43-2.65)^{* * *}$ & $1.63(1.13-2.37)^{*}$ \\
\hline No & $96(42.30)$ & $352(58.80)$ & 1.00 & 1.00 \\
\hline \multicolumn{5}{|l|}{ Emotional Violence } \\
\hline Yes & $168(74.00)$ & $363(60.60)$ & $1.85(1.32-2.59)^{* * *}$ & $1.32(0.87-2.00)$ \\
\hline No & $59(26.00)$ & $236(39.40)$ & 1.00 & 1.00 \\
\hline \multicolumn{5}{|l|}{ Adolescence Sexual V. } \\
\hline Yes & $69(30.40)$ & $100(16.70)$ & $2.18(1.53-3.11)^{* * *}$ & $1.59(1.01-2.52)^{*}$ \\
\hline No & $158(69.60)$ & 499 (83.30) & 1.00 & 1.00 \\
\hline \multicolumn{5}{|l|}{ Contraceptive Use } \\
\hline Yes & $26(11.50)$ & $94(15.70)$ & $0.69(0.44-1.10)^{* * *}$ & $2.19(1.31-3.67)^{* *}$ \\
\hline No & 201 (88.50) & $505(84.30)$ & 1.00 & 1.00 \\
\hline
\end{tabular}

COR Crude Odds Ratio, AOR Adjusted Odds Ratio

N.B. ${ }^{*}=p$-value $<0.05,{ }^{* *} p$-value $<0.01,{ }^{* * *} p$-value $<0.001$ 
However, in this study there is no significant association identified between depression and educational status, service year, DSLE, sexual violence (under 15 \& life time) and emotional violence.

\section{Factors associated with anxiety:}

The binary logistic (crude analysis) was done on sociodemographic (Age, marital status, educational status, service year, salary, family visit and parent's relationship status), clinical (medical condition, contraceptive use); psychosocial factors (alcohol use, khat use, stress full life events, life time physical and sexual violence, under 15 sexual violence and domestic violence, ) were found to be p-value of less than 0.2 in Univariate logistic regression and taken in to multivariable logistic regression. The variable group expected to be protective against anxiety is treated as the reference group (Table 5).

The odds of developing Anxiety decreased by 38\%; $(\mathrm{AOR}=0.68,95 \% \mathrm{CI}=0.42-0.92)$; among participants living with relatives when it compared with relatives living at place possible to visit.

The odds of developing anxiety is 3.92; $(\mathrm{AOR}=3.92$, 95\% CI= $1.99-7.69$ ); times increased among divorced participants when it compared with single one.

The odds of developing Anxiety is 2.63; $(\mathrm{AOR}=$ 2.63, 95\% CI=1.06 - 6.56); times higher among participants living with employers when it compared with housemaids who visit their relatives more frequently.

When compared with participants whose parents are living together, the risk of developing anxiety is 2.45; $(\mathrm{AOR}=2.45,95 \% \mathrm{CI}=1.23-4.89)$; times increased among housemaids from divorced parents, 1.98; (AOR= 1.98, 95\% CI=1.30 - 3.02); times increased among housemaids who lost father/mother, and 1.13 (AOR= $1.13,95 \% \mathrm{CI}=0.58-2.19)$ times increased among housemaids who lost both parents.

The odds of developing anxiety is 1.59; $(\mathrm{AOR}=1.59$, $95 \% \mathrm{CI}=1.09-2.33)$ times more among housemaid who have physical violence.

The odds of developing anxiety is 1.72 ; $(\mathrm{AOR}=1.72$, $95 \% \mathrm{CI}=1.07-2.78$ ) times more among housemaid who have sexual violence when it compared with no sexual violence.

The risk of developing anxiety is 2.03; $(\mathrm{AOR}=2.03$, $95 \% \mathrm{CI}=1.18-3.50$ ); times increased among housemaids who are using contraceptive than who are not using contraceptive.

However, in this study there is no significant association identified between age, educational status, salary, service year, substance (khat, alcohol, cigarette) use , DSLE, sexual violence (under 15 \& life time) and emotional violence.

\section{Discussion, Conclusion and Recommendations Discussion}

In this study; the prevalence of depression, prevalence of anxiety, possible factors associated with depression and factors associated with anxiety were assessed; prevalence of depression and anxiety is $27 \%$ and $32 \%$ respectively. Also coincidence of depression with anxiety was analyzed. It was found $44.6 \%$ mild form of comorbid depression with anxiety, $18.5 \%$ moderate form of comorbid depression with anxiety and $8.1 \%$ severe forms of depression comorbid with anxiety.

Findings on prevalence of depression and anxiety is supported by different studies done in Kuwait among housemaids; which describes Psychiatric morbidity among housemaids is two to five times higher than the native female population [7-9].

This finding is higher when compared with the study conducted in Florence (22.8 \% depression and 17.2\% Anxiety) [5]. The possible reason might be that study conducted among women in general population and this study focus on specific group of population (housemaids) with possibly low socioeconomic characteristics.

Prevalence of depression is higher when it compared with the study done in Mozambique (14\%) female heads of household [17]. This difference might be because of the tool used to assess depression. They use PHQ-8, which assess each item of depression and value equally for each item as a screening tool. In case of our study we use PHQ-4, which has two gait symptoms of depression and anxiety for each. Also the study participants are in different status at the household; the head and the servant.

Prevalence of depression is higher when it compared with the study conducted among all Ethiopian women (age 15 - 49) was 4.4\% [18]. This difference may occur due to risky age group and socioeconomic status of participants for the study problem. Another study conducted in Ethiopian immigrants at Toronto is less (9.8\%) when compare with our study [19].

The odds of developing depression 2.62 times increased among divorced participants when it compared with single one. Also the odd of developing anxiety is 3.92 times increased among those groups of participants when it compared with single one. This finding is supported by the study done in Ethiopian women that explain; odds ratio increased for divorced, separated or widowed women than for not-married women (4.05 and 4.24, respectively) [18].

The odd of developing depression is 2.10 times increased among participants whose parents are divorced and the risk of anxiety is 2.45 times increased among them. This finding is supported by study finding Increased risk for major depression and generalized anxiety disorder was associated with parental separation but 
Table 5 Factors which has association with anxiety on binary logistic regression: Addis Ababa, Ethiopia- 2018

\begin{tabular}{|c|c|c|c|c|}
\hline \multirow[t]{3}{*}{ Variables } & \multicolumn{4}{|c|}{ Results: $\boldsymbol{n}=826$} \\
\hline & \multicolumn{2}{|l|}{ Anxiety } & \multirow[t]{2}{*}{ COR (Cl 95\%) } & \multirow[t]{2}{*}{ AOR (CI 95\%) } \\
\hline & Yes (\%) & No (\%) & & \\
\hline \multicolumn{5}{|l|}{ Age } \\
\hline$<15$ & $13(4.90)$ & $16(2.90)$ & $1.53(0.71-3.29)$ & $1.89(0.79-4.53)$ \\
\hline 16 to 20 & $112(41.90)$ & $227(49.60)$ & $0.76(0.55-1.05)^{*}$ & $0.83(0.56-1.21)$ \\
\hline 21 to 25 & $30(11.20)$ & $55(9.80)$ & $1.03(0.62-1.69)$ & $0.71(0.38-1.33)$ \\
\hline$>25$ & $112(41.90)$ & $211(37.70)$ & 1.00 & 1.00 \\
\hline \multicolumn{5}{|l|}{ Educational status: } \\
\hline No formal Education & $44(19.40)$ & $83(13.90)$ & $0.62(1.96-1.95)$ & $0.28(0.08-0.98)^{*}$ \\
\hline Primary level & $134(59.00)$ & $309(64.90)$ & $0.40(0.13-1.22)^{*}$ & $0.24(0.07-0.82)^{*}$ \\
\hline Secondary level & $43(18.90)$ & $120(20.00)$ & $.042(0.13-1.13)^{*}$ & $0.25(0.07-0.87)^{*}$ \\
\hline College level & $6(2.60)$ & $7(1.20)$ & 1.00 & 1.00 \\
\hline \multicolumn{5}{|l|}{ Salary } \\
\hline$<500$ & $4(1.50)$ & $32(5.70)$ & $0.19(0.58-0.63)^{* *}$ & $0.25(0.02-2.72)$ \\
\hline $501-1000$ & $161(60.30)$ & $309(55.30)$ & $0.79(0.43-1.46)$ & $1.45(0.25-8.21)$ \\
\hline $1001-1500$ & $48(18.00)$ & $126(22.50)$ & $0.58(0.29-1.13)^{*}$ & $0.93(0.21-4.06)$ \\
\hline $1501-2000$ & $35(13.10)$ & $63(11.30)$ & $0.85(0.42-1.73)$ & $1.31(0.42-4.13)$ \\
\hline$>2000$ & $19(7.10)$ & $29(5.20)$ & 1.00 & 1.00 \\
\hline \multicolumn{5}{|c|}{ Relatives Distant (how far if your families?) } \\
\hline Nearest as possible to visit & $167(62.50)$ & $377(67.40)$ & 1.00 & 1.00 \\
\hline Not found nearly & $2(0.70)$ & $7(1.30)$ & $0.36(0.10-1.30)$ & $2.63(0.62-11.11)$ \\
\hline Living with them & $92(34.50)$ & $171(30.60)$ & $0.29(0.08-1.06)^{*}$ & $0.62(0.42-0.92)^{*}$ \\
\hline I don't know where they are & $6(2.20)$ & $4(0.70)$ & $0.19(0.02-1.43)$ & $3.30(0.69-15.78)$ \\
\hline \multicolumn{5}{|l|}{ Relationship status } \\
\hline Single & $200(74.90)$ & $460(82.30)$ & 1.00 & 1.00 \\
\hline Separated & $26(9.70)$ & $60(10.70)$ & $0.99(0.61-1.36)$ & $1.20(0.67-2.15)$ \\
\hline Divorced & $35(13.10)$ & $31(5.50)$ & $2.59(1.56-4.33)^{* * *}$ & $3.92(1.99-7.69)^{* * *}$ \\
\hline Widowed & $4(1.50)$ & $2(0.4)$ & $4.60(0.84-25.32)^{*}$ & $1.56(0.20-12.22)$ \\
\hline Married & $2(0.70)$ & $6(1.10)$ & $0.77(0.15-3.83)$ & $1.19(0.22-6.61)$ \\
\hline \multicolumn{5}{|c|}{ Vacation (how frequent do you visit your families?) } \\
\hline Less than monthly & $26(9.70)$ & $99(17.70)$ & 1.00 & 1.00 \\
\hline Monthly & $56(21.00)$ & $118(21.10)$ & $1.891(1.06-3.09)^{*}$ & $1.07(0.59-1.96)$ \\
\hline Monthly to yearly & $56(21.00)$ & $129(23.10)$ & $1.65(0.97-2.82)^{*}$ & $0.59(0.32-1.12)$ \\
\hline More than Yearly & $117(43.8)$ & $190(34.00)$ & $2.34(1.44-3.82)^{* *}$ & $1.15(0.65-2.04)$ \\
\hline Living with employer & $12(4.50)$ & $23(4.10)$ & $1.99(0.87-0.51)$ & $2.63(1.06-6.56)^{*}$ \\
\hline \multicolumn{5}{|c|}{ Parent condition (Parent Relationship status) } \\
\hline Living together & $113(42.30)$ & $295(52.80)$ & 1.00 & 1.00 \\
\hline Separated & $31(11.60)$ & $51(9.10)$ & $1.59(0.97-2.61)^{*}$ & $1.12(0.59-2.10)$ \\
\hline Divorced & $25(9.40)$ & $28(5.00)$ & $2.33(1.30-4.19)^{* *}$ & $2.45(1.23-4.89)^{*}$ \\
\hline Mother/ father lost & $74(27.70)$ & $138(24.70)$ & $1.40(0.98-1.99)^{*}$ & $1.98(1.30-3.02)^{* *}$ \\
\hline Both parents lost & $24(9.00)$ & $47(8.40)$ & $1.33(0.78-2.28)$ & $1.13(0.58-2.19)^{* *}$ \\
\hline \multicolumn{5}{|c|}{ Parent support: If problems happen, how hard is getting family support? } \\
\hline Yes & $106(41.20)$ & $28.90(51.70)$ & $0.65(0.49-0.89)^{* *}$ & $1.67(1.16-2.42)^{* *}$ \\
\hline No & $157(58.80)$ & $270(48.30)$ & 1.00 & 1.00 \\
\hline
\end{tabular}


Table 5 Factors which has association with anxiety on binary logistic regression: Addis Ababa, Ethiopia- 2018 (Continued)

\begin{tabular}{|c|c|c|c|c|}
\hline \multirow[t]{3}{*}{ Variables } & \multicolumn{4}{|c|}{ Results: $\boldsymbol{n}=826$} \\
\hline & \multicolumn{2}{|l|}{ Anxiety } & \multirow[t]{2}{*}{ COR (Cl 95\%) } & \multirow[t]{2}{*}{ AOR (CI 95\%) } \\
\hline & Yes (\%) & No (\%) & & \\
\hline \multicolumn{5}{|c|}{ Physical Violence: while working as house maid } \\
\hline Yes & $153(57.30)$ & $225(40.30)$ & $1.99(1.48-2.68)^{* *}$ & $1.59(1.09-2.33)^{*}$ \\
\hline No & $114(42.70)$ & $334(59.70)$ & 1.00 & 1.00 \\
\hline \multicolumn{5}{|c|}{ Sexual Violence: while working as house maid } \\
\hline Yes & $93(34.80)$ & $76(13.60)$ & $3.39(2.39-4.82)^{* * *}$ & $1.72(1.07-2.78)^{*}$ \\
\hline No & $147(65.20)$ & $483(86.40)$ & 1.00 & 1.00 \\
\hline \multicolumn{5}{|l|}{ DSLE: } \\
\hline Yes & $96(36.00)$ & $121(21.60)$ & $2.03(1.47-2.80)^{* * *}$ & $1.51(1.04-2.19)^{*}$ \\
\hline No & $171(64.00)$ & $438(78.40)$ & 1.00 & 1.00 \\
\hline \multicolumn{5}{|c|}{ Contraceptive Use } \\
\hline Yes & $106(41.20)$ & $289(51.70)$ & $0.73(0.47-1.12)^{*}$ & $2.03(1.18-3.50)^{*}$ \\
\hline No & $157(58.80)$ & $270(48.30)$ & 1.00 & 1.00 \\
\hline
\end{tabular}

COR Crude Odds Ratio, AOR Adjusted Odds Ratio

N.B. ${ }^{*}=p$-value $<0.05,{ }^{* *} p$-value $<0.01,{ }^{* * *} p$-value $<0.001$

not parental death and with separation from either mother or father [20]. But it is against finding on parent's death. In this study, parent lost has positively associated with depression and anxiety (father/mother lost 1.98 times for both anxiety \& depression. Also death of both parents is 1.13 times associate with anxiety) [20].

The risk of developing Depression and Anxiety is increased among participants who had physical violence (1.63 times for depression \& 1.59 times for anxiety) and sexual violence (1.59 times for depression and 1.72 times for anxiety). This finding supported by the study conducted in Nicaragua. It states that, 'Women reporting abuse (any form) were 6 times more likely to experience emotional distress' [21].

The risk of developing depression and anxiety is (2.19 and 2.03 times respectively) increased among contraceptive users when it compared with participants not using contraceptive.

The odds of developing depression decreased by $74 \%$, $75 \%$ and $72 \%$ among participants at primary, secondary or tertiary level of education respectively, when it compared with participants who are not educated. This finding is supported by the study conducted in Mozambique; it explains increased risk of depression when additional year of education (AOR: 1.06) [17]

The odd of developing Anxiety is decreased by $38 \%$ among participants living with relatives. This finding is supported by Mozambique's study, additional kilometer from home is risky to develop mental distress (AOR: 1.05) [17]. Also other study explain support from immediate superior find the most consistent protective factor (OR 0.56, 99\% CI: 0.43-0.72) among other factors [22].
Unlike other studies, in this study service year, salary, under 15 sexual violence, age, substance use, emotional violence and other variables do not appear to have an independent effect on depression or anxiety $[17,18]$.

\section{Limitation}

This study has limitation on variables temporal relationship and social desirability bias may affect it. Also as a factor employers don't consider as a factor despite it has impact on the variable.

\section{Conclusion}

The prevalence of depression and anxiety among housemaid found to be higher at Addis Ababa. Its prevalence is more among age group 16 to 20 . This study gives an indication of specific health care needs of women working in household and it is significant public health problem that require a great emphasis. This study weighted the data from Addis Ababa, 2018 to succeed in identifying a statistically significant association on depression and anxiety. The following variables; Educational status, parental relationship, divorce, violence (physical and sexual), contraceptive use and daily stressful life events are found statistically significant.

Preventive measures involving recruitment procedures and pre-employment orientation are needed to minimize the impact of factors on mental health.

\section{Recommendation}

Based on findings and conclusions made, the following recommendations were given for responsible organs.

To Federal Ministry of health and Addis Ababa health bureau 
$>$ Consider addressing those groups of female mental health need to achieve health for all agenda

$>$ Provide psychological and social support

\section{To Ethiopia Ministry of Women, Children and Youth Affairs: \\ $\triangleright$ To arrange possible psychosocial support for those groups of population}

\section{For Researchers:}

$>$ Further scientific efforts should be made to find out other family and employer related factors

\begin{abstract}
Abbreviations
AMSH: Amanuel Mental Specialized Hospital; AOR: Adjusted Odds Ratio; $\mathrm{Cl}$ : Confidence interval; CIDI : Composite International Diagnostic Interview; DSLEMS: Daily Stress Full Life Events Measurement Scale; GAD: Generalized Anxiety Disorder; PHQ-4: Patient Health Questionnaire -4; PI: Principal Investigator; RW CD: : Reader and Writer Compact Disc; SPSS-20 : Statistical Package for Social Sciences version 20; St: Saint; WHO: World Health Organization
\end{abstract}

\section{Acknowledgments}

The Authors would like to acknowledge Amanuel Mental Specialized Hospital Research and Training Center; and Addis Ababa City Administration and Sub Cities for their timely administrative supports to complete this study. The Author would also like to thank all household heads who were facilitating data collection procedure; all study participants, all data collectors and supervisors.

\section{Authors' contributions}

AE: Principal Investigator, Corresponding author; Participated in the conception and design of the study, wrote the proposal, participate in data analysis and write up of this manuscript. ZS, M.G/L.: Consulted on proposal development, report writing, presentation, manuscript writing and approval of final manuscript. TJ: Consultation on proposal development, report writing \& presentation. Z.S., M.G/L. and Y.H.: Participated on training of data collectors, supervision, data management, entry and analysis of data. All authors read, revised and approved the final manuscript

\section{Authors' information}

A.E. is principal investigator, Corresponding author; Mental Health Professional Specialist, Adult Educator, and Research Team leader at St. Amanuel Mental Specialized Hospital

Z.S. - author, Mental Health Professional Specialist at St. Amanuel Mental Specialized Hospital

M.G/L. - author, Mental Health Professional Specialist at St. Amanuel Mental Specialized Hospital

T.J. - author, Mental Health Professional Specialist and Research Director at St. Amanuel Mental Specialized Hospital

Y. H. - Mental Health Professional Specialist - St. Amanuel Mental Specialized Hospital

\section{Funding}

This study was partially funded by St. Amanuel Mental Specialized Hospital Research and Training Directorate. It covers secretarial expenditure, data collectors' fee, temple development and data entry costs. Data analysis, data interpretation data, report writing and manuscript development were covered by all authors.

\section{Availability of data and materials}

The datasets generated and analyzed during this study are available as supplementary information file

\section{Ethics approval and consent to participate}

Ethical clearance was obtained from Ethical Review Board of AMSH Research and Training Center. An official permission letter was obtain from Addis Ababa Health Bureau and selected sub city administrative organs. Then, after explaining the aim and the purpose of the study to each employer (house head) we contact housemaids to collect the data.

Following that, the purpose, importance and confidentiality of the study were well explained to each study participants before they engage in to actual activities. Finally written consent obtained from each housemaid in the age group 18 and above. For study participants under the age of eighteen (11.5\%; ninety five participants), assent was taken from their guardian. Confidentiality was maintained at all levels of the study by avoiding use of name, specific age, actual salary and other identifiers. Participants were informed that they will never get any benefit because of part of the study and no harm on them if they were not agree to participate or withdraw at any stage of data collection.

Participants' privacy was kept by preparing possible temporary data collecting corner at their place. Nine participants with complains of suggestive anxious and depressed feelings were recommended to visit nearby health facility for further evaluation and possible managements.

\section{Consent for publication}

Not applicable

\section{Competing interests}

The authors declare that they have no competing interest

\section{Author details}

'Postcode 185093 Addis Ababa, Ethiopia. ${ }^{2}$ Postcode 1971 Addis Ababa, Ethiopia.

Received: 27 August 2019 Accepted: 30 April 2020

Published online: 13 May 2020

\section{References}

1. Allen M, Raghallaigh MN. Women's Experiences of Gender Based Violence in Tigray, Ethiopia; 2012.

2. Baxter A, Scott $K$, Vos $T$, Whiteford H. Global prevalence of anxiety disorders: a systematic review and meta-regression. Psychol Med. 2013;43(5):897-910.

3. Parker G, Fletcher K, Paterson A, Anderson J, Hong M. Gender differences in depression severity and symptoms across depressive sub-types. J Affect Disord. 2014;167:351-7.

4. Weissman MM, Klerman GL. Sex differences and the epidemiology of depression. Arch Gen Psychiatry. 1977:34(1):98-111.

5. Faravelli C, Scarpato MA, Castellini G, Sauro CL. Gender differences in depression and anxiety: the role of age. Psychiatry Res. 2013;210(3):1301-3.

6. Kessler RC. Epidemiology of women and depression. J Affect Disord. 2003; 74(1):5-13.

7. Zahid MA, Fido A, Alowaish R, Mohsen MAE-M, Razik MA. Psychiatric morbidity among housemaids in Kuwait III: Vulnerability factors. Int J Soc Psychiatry. 2003:49(2):87-96.

8. El-Hilu SM, Mousa R, Abdulmalek H, Kamel N, Zohdi M, Maher A, Al-Aamriti M. Psychiatric morbidity among foreign housemaids in Kuwait. Int J Soc Psychiatry. 1990;36(4):291-9.

9. Zahid M, Fido A, Razik M, Mohsen M, El-Sayed A. Psychiatric morbidity among housemaids in Kuwait. Med Princ Pract. 2004;13(5):249-54.

10. Sales EC, Santana VS. Depressive and anxiety symptoms among housemaids. Am J Ind Med. 2003:44(6):685-91.

11. Rehn E, Johnson Sirleaf E. Women, War and Peace, Progress of the World's Women. New York: UNIFEM; 2002.

12. Hsieh Y-CJ, Apostolopoulos Y, Sönmez S. The world at work: hotel cleaners. Occup Environ Med. 2013:70(5):360-4

13. Allen M, Raghallaigh MN. Domestic violence in a developing context: The perspectives of women in northern Ethiopia. Affilia. 2013;28(3):256-72.

14. Kumar A. Domestic violence in India: Causes, consequences and remedies. Youth ki awaaz. 2010. https://www.youthkiawaaz.com/2010/02/domesticviolence-in-india-causes-consequences-and-remedies-2/.

15. Löwe B, Wahl I, Rose M, Spitzer C, Glaesmer H, Wingenfeld K, Schneider A, Brähler E. A 4-item measure of depression and anxiety: validation and standardization of the Patient Health Questionnaire-4 (PHQ-4) in the general population. J Affect Disord. 2010;122(1):86-95.

16. Ellsberg $M$, Jansen $H$, Heise $L$, Watts $C H$, Garcia-Moreno C. WHO Multicountry Study on Women's Health and Domestic Violence against Women Study Team. Intimate partner violence and women's physical and mental 
health in the WHO multi-country study on women's health and domestic violence: an observational study. Lancet. 2008;371(9619):1165-72.

17. Audet $C M$, Wainberg ML, Oquendo MA, Yu Q, Peratikos MB, Duarte CS, Martinho S, Green AF, González-Calvo L, Moon TD. Depression among female heads-of-household in rural Mozambique: A cross-sectional population-based survey. J Affect Disord. 2018;227:48-55.

18. Deyessa N, Berhane Y, Alem A, Hogberg U, Kullgren G. Depression among women in rural Ethiopia as related to socioeconomic factors: a communitybased study on women in reproductive age groups. Scand J Public Health. 2008;36(6):589-97.

19. Fenta H, Hyman I, Noh S. Determinants of depression among Ethiopian immigrants and refugees in Toronto. J Nerv Ment Dis. 2004;192(5):363-72.

20. Kendler KS, Neale MC, Kessler RC, Heath AC, Eaves L. Childhood parental loss and adult psychopathology in women: a twin study perspective. Arch Gen Psychiatry. 1992;49(2):109-16

21. Ellsberg M, Caldera T, Herrera A, Winkvist A, Kullgren G. Domestic violence and emotional distress among Nicaraguan women: Results from a population-based study. Am Psychol. 1999;54(1):30.

22. Finne LB, Christensen JO, Knardahl S. Psychological and social work factors as predictors of mental distress: a prospective study. PLoS One. 2014;9(7): e102514.

\section{Publisher's Note}

Springer Nature remains neutral with regard to jurisdictional claims in published maps and institutional affiliations.

Ready to submit your research? Choose BMC and benefit from:

- fast, convenient online submission

- thorough peer review by experienced researchers in your field

- rapid publication on acceptance

- support for research data, including large and complex data types

- gold Open Access which fosters wider collaboration and increased citations

- maximum visibility for your research: over $100 \mathrm{M}$ website views per year

At BMC, research is always in progress.

Learn more biomedcentral.com/submissions 